throat, which caused him some distress. Said he felt a difficulty in breathing, though the respiration was but slightly embarrassed. The superficial temporal and frontal veins were very distinct and tortuous, being gorged with blood. He could not walk by himself, but, if supported, walked with an unsteady gait, though he had perfect control over his upper extremities. Still felt intoxicated, and his body hot. Pulse 96, full and strong; respiration 26; temperature $1005^{\circ}$. Occasionally retching. He had no medicines, except a few innocent articles-such as cloves, ginger, tea-soon after he was bitten. Of course, the "snake-charmers" had been to work with their charms and incantations, and I have no doubt this case will go far to establish the reputation of the men who have been in attendance, especially as I confined myself merely to watching its progress. - 11.30 A.M. : Is slightly better, but still feels intoxicated. Temperature $101 \cdot 10^{\circ}$.-1 P.M.: Temperature $101.5^{\circ}$ - -2.30 P.M.: Arm a little more swollen; now meastures eleven inches and a half. Has passed a large quantity of urine; no fæces. Feels slightly sick, and the veins about the face are still gorged. Temperature $101.3^{\circ}$; pulse 88 . Now speaks distinctly without the nasal intonation; can swallow; is, in fact, fast recovering, though suffering rather severely from the pain in the arm.

From this time he rapidly recovered, and the arm got quite well, very little suppuration having taken place at the incised part-another proof that but a very small quantity of poison had been injected into the subcutaneous areolar tissue. The patient did not suffer subsequently from any symptoms of blood-poisoning. It is very seldom, indeed, that a cobra, in its wild state, poisons without killing; hence it is more than probable that it had expended most of the poison at its disposal in attacking the rats, the squeaking of which had awoke the patient. There is reason to believe that some of the snake-poison must have been injected directly into one of the small venous branches of the skin. This case shows how seriously affected the functions of certain centres of the medulla oblongata may become in snake-poisoning, without permanent injury resulting.

Goalundo.

\section{CASE OF LACERATED WOUND OF THE FOOT.}

BY HENRY F. NORBURY, STAFF-SURGEON R.N.

Communicated by the DiREcror-General of THE Medical DePart. MENT OF THE NAYY.)

J. L-, aged twenty-three, a temperate but somewhat anamic subject, on the afternoon of July 27 th, during a gale in the tropics, attempted to step from a ship into a boat, which rising simultaneously on the top of a wave, crushed his left foot against the ship's side, tearing his boot to pieces and inflicting very severe injuries to the soft parts. On examination, the entire integument was found torn away from the dorsum from the front of the ankle to within an inch of the toes, and as far inwards as the tendon of the extensor proprius pollicis muscle, over which it lay in folds. A similar laceration existed on the under surface of the foot, the pasterior three-fourths of the sole being stripped off, a narrow bridge of skin on the inner side alone dividing the former from the latter lesion; a few minor patches of integument were likewise wanting about the malleoli. The hæmorrhage was slight. The divided integument was laid down, but there was only sufficient partially to cover the exposed muscles and tendons, and the entire foot was enveloped in lint soaked in carbolic oil a gutta-percha L-shaped splint being placed along the inner side of the foot and ankle, to ensure rest.

As there was considerable sanious oozing and some fetor, the dressings were changed on the following day, and although perfect cleanliness was preserved, on the evening of the 29th traumatic fever appeared. The wounds in a short time began to look sloughy, the skin on the front of the ankle assuming a livid red character. Symptoms of septicæmia followed, but as the system was well supported and he was kept a great part of his time in the open air, these gradually passed off after an attack of diarrhoea, evidently of an eliminative nature.
On August 4th, by which time the temperature had become normal, the integument constituting the firstmentioned laceration came away as a slough, leaving a feeble granulating surface, the granulations being pale large, and watery, secreting a thin puriform fluid. The heel also began to slough. He was now ordered ten-minim doses of tincture of opium thrice daily, the good effects of which treatment $I$ had often witnessed in cases of weak ulcer when acting as dresser to the late Mr. Skey, C.B., at St. Bartholomew's Hospital.

On the 7th a line of demarcation appeared across the sole, about two inches posterior to the toes. Charcoal poultices were applied, and on the 11th the gangrenous mass: separated, consisting of the integument, part of the plantar fascia, and a portion of the first layer of muscles. The only part of the foot which now possessed a covering of skin was a small area on the inner side, and the excavated part of the sole for some time presented a dry, glassy surface, exuding a thin, sanious matter. Granulations, however, gradually appeared, while those on the dorsum had acquired a more florid look, and discharged a thick, creamy pus.

By the 17th the entire surface was in a condition of healthy. suppuration, and although the patient had been formerly: feeble, he had, by this time, greatly improved under the use of the small doses of laudanum. Skin-grafting was now practised, a piece being removed from the outer side of the arm, and about a dozen minute grafts laid down, which were then covered by strips of plaster, the operation being subsequently repeated. A large proportion of these " took," and by the $29 t h$ varied in size from half a split pea to a threepenny piece, the raw surface putting on such action that it had to be kept under by applying solid sulphate of copper. The patient's health had much improved, and he began to get some colour in his face; his strength throughout had been well supported, and the opium had been con. stantly administered. By Oct. 1st the wound had completely healed, a firm cicatrix remaining, and his general appear. ance was much better than before the accident.

Remarks.-It must be taken into consideration in this case that a very extensive surface of the foot was denuded of integument, in addition to muscular laceration, and how much more serious an injury of this part of the lower extremity is than the corresponding portion of the upper; in many cases amputation might have been necessary. My object in publishing this case is simply to record the fact that granulation proceeds much more perfectly, and satisfactorily, and rapidly in cases of skin-grafting, when a prolonged course of small doses of tincture of opium is persevered with ; I also think that under its influence the grafts become adherent more readily and in unusual numbers. In this instance the result, without its agency, would have been extremely doubtful.

\section{d a thlitror}

\section{HOSPITAL PRACTICE,}

\section{BRITISH AND FOREIGN.}

Nulla autem est alia pro certo noscendi via, nisi quampluximas et morbornm : et dissectionum historias, tum aliorum, tum proprias collectas habere, ev inter se comparare.-MorgaGNI De Sed. et Caus. Morb., lib. iv. Procmium.

\section{CHARTNG-CROSS HOSPTTAT.}

IDIOPATHIC AMYLOID DISEASE OF THE LIVER, KIDNEY AND SPLEEN ; RELIEF ; REMARKS.

(Under the care of Dr. Julius Pollock.)

For the following interesting notes we are indebted to Mr. Robert Smith, M.A., M.B., medical registrar.

William D - a labourer, aged twenty-six years, was admitted on Feb. 9th, complaining chiefly of weakness. He fixed the beginning of his illness three months before admission. About that time, while waiting upon his father, who was seriously ill, he had several shivering fits. The sensations of cold were mostly confined to the back, and resembled the pouring of cold water down the spine. At night, after the shiverings, he sweated freely. The shiverings continued on and off for a fortnight, but the patient continued to nurse his father until his death at Christmas. 
The father was said to have had enlargement of the liver. Cough now came on, and the patient began to spit tenacious phlegm of a dark colour. He lost flesh, and gradually grew weaker; but after the first week or two he was not feverish, and did not perspire unduly. About a fortnight before admission he once or twice felt severe pain at the pit of the stomach, relieved by taking hot gin-and-water and applying hot flannels to the abdomen. He had no other uneasiness, but gradually got weaker, and his appetite diminished. His previous history was good. He never had rheumatism or gout or any venereal affection. He married very young, and had had a family of four children, all quite healthy. He had not been in the habit of drinking spirits. His bowels were usually regular. His mother died of "inability to pass gall-stones," and used to be jaundiced now and then; and his father died, as just stated, of " enlargement of the liver"; his father's legs andfeetswelled before death, but he had never been jaundiced, and was very pale when he died. Patient had four brothers and sisters alive and well.

On admission, he was a tall, sparely-built young man, with very pale features and anæmic mucous membranes; but he stated that he had always been pale. He was suffering no pain, and there was only a slight cough. The
evening temperature was $101.5^{\circ} \mathbf{F}$, at which point it continued for three days thereafter. The pulse was about 100 . His skin felt quite moist, but there was no marked perspiration at night. He slept very well, and said his appetite was improving. The skin over his whole body was exceedingly pale. Physical examination of the chest revealed nothing of importance in regard either to lungs or heart. The region of liver dulness was increased, so as to extend downwards half way between the costal cartilages and the level of the umbilicus. There was not any tenderness on pressure over the liver region, or anywhere over the abdomen. The spleen was also found to be enlarged. He suffered sometimes from flatulence. On the two sides of the chest and abdomen there were a few small rounded papules, slightly raised above the level of the skin, and of a faintly reddish colour. There were also one or two similar papules on each arm. On the 12th he passed sixteen ounces of urine, sp. gr. 1020, acid, and containing one twentieth part of albumen, but no sugar or casts. Ordered milk and beef-tea diet. To take five grains of iodide of potassium in saline mixture three times a day.

On the 14th the patient's evening temperature fell to $100.5^{\circ}$. That day he passed only eight ounces of urine, which still contained a small quantity of albumen, but no casts. On the 16 th he complained of some soreness of throat, the result of fresh cold. His appetite continued to improve. To take five grains of chlorate of potash in one ounce of perchloride of iron mixture three times a day.

On the 26th the patient felt much better, and was not quite so anæmic. His temperature had gradually fallen from the 15th, and had been normal for two days. He now passed about sixty ounces of urine in the twenty-four hours. It still contained a small quantity of albumen. The liver and splenic dulness have diminished in area.

On March 12th the patient continued to improve, and went out to-day.

Remarks by Dr. JuluUs PoLLock.-This case is one of some interest, being apparently an instance of idiopathic amyloid disease of the liver, spleen, and kidneys. When first seen the great enlargement and "rounding" of the liver was most remarkable, and the existence of a somewhat enlarged spleen and of albumen in the urine makes it pretty clear that the spleen and kidneys were likewise affected. Contrary to expectation, the patient began to get better from the moment of his coming into the hospital, and before he left the liver was scarcely larger than normal, and there was but a trace of albumen in the urine. The cause of the amyloid change in this case is quite obscure.

\section{WEST LONDON HOSPITAL.}

STRICTURE OF THE URETHRA AND STONE IN THE BLADDER ; MEDIAN LITHOTOMY; RELAPSE OF THE STRIOTURE THREE YEARS AFTERWARDS; EXTERNAL URETHROTOMY ; GOOD RESULT.

(Under the care of Mr. TEEvaN.)

GEORGE D-, a mechanic, forty-six years old, was admitted into the hospital on March 10th, 1874. He stated that he caught a gonorrhoea twenty-five years ago, which was treated by medicines and injections; it gradually dwindled into a gleet, which hung about him for some time. Fourteen years ago he had such difficulty in mictu. rition that he went into a hospital, where his stricture was treated by gradual dilatation. He remained tolerably well for some time, when he experienced a relapse, and entered another hospital, where he went through a course of treatment similar to that on the previous occasion. The largest instrument which could be passed at either course was No. 9 (English), and if an attempt were made to intro. duce No. 10, it was followed by a rigor.

When admitted into the West London Hospital, he was obliged to micturate every ten minutes or so, and could only eject a few drops of urine by straining forcibly. There was a considerable amount of muco-pus in the urine, and he complained of much pain in the loins. His body was well nourished, his appearance healthy, but his expression was indicative of much physical suffering. No instrument, soft or metal, could be passed through the stricture, which com. menced four inches and a half from the meatus externus. The patient was kept quiet in bed, purged, and his perineum leeched. Every other day attempts were made to pass different instruments, the patient having previously intro. duced a bougie as far as it would go, and kept it pressing against the stricture for half an hour, in order to dilate its mouth. The "bougie armée" was used on four occasions, but the treatment did not agree with him, although it apparently did much good, for on April 29th Mr. Teevan managed to pass a fine olivary whalebone bougie into the bladder, and tied it in for twelve hours. On May 6th he introduced a similar bougie as on the former occasion, and then attempted to slide over it a No. 1 (English) silver catheter open at both ends. Whilst endeavouring to make the metal tube pass over the angle in the bougie at the sub. pubic curve, the bougie was cut in two. A part (about two thirds) of the instrument was withdrawn, but the remaining portion, some four inches long, could not be extracted, and was left in the bladder. The patient experienced no incon. venience, and as he was passing a better stream of urine, he left the hospital three days afterwards, to be treated as an out-patient

By June 30th his stricture had, by gradual dilatation, been enlarged to No. 14 French gauge. He complained of suffering considerable pain from time to time in the left loin, and occasionally passed small, black, pultaceous. looking threads, which were evidently pieces of the disintegrated bougie.

On October 5th he was readmitted, as he was troubled to micturate very frequently and experienced a good deal of pain in the left loin and down the penis. As the patient's symptoms pointed to the presence of a stone in the bladder, as the stricture would now only admit a very small instru ment, as the healthy urethra was naturally very small, and as continuous or gradual dilatation was followed by rigors which greatly prostrated the patient, and interrupted the treatment, Mr. Teevan determined to divide the stricture externally and extract the stone, which he knew must be soft and small, through the opening.

On Oct. 17th the patient was put under the influence of ether and a No. 3 (English) catheter staff having been introduced into the bladder by Mr. Teevan, he divided the stricture, which was two inches long, externally, passed a long urethral forceps into the bladder and extracted the three fragments into which the stone had broken when grasped. The pieces, when put together, represented a calculus about as large as a damson, and weighed ninety grains; the largest piece had as a nuclens a portion, about half an inch long, of the broken bougie. The daily records of the temperature, as taken by Mr. Webber, the house-surgeon, showed that there was scarcely any constitutional disturbance after the operation, and the patient left the hospital with the wound quite healed on Nov. 7th, the urethra admitting No. 16 of the French gauge. He attended a few times as an out-patient, and then discontinued his visits.

On May 14th, 1877, he was again admitted, as his stricture had recontracted, and would only take No. 2 English. He was treated by continuous and gradual dilatation, but as little progress was made, and as the introduction of instru. ments was very painful and attended by much constitutional disturbance, often culminating in rigors, Mr. Teevan decided to perform external urethrotomy. Accordingly, on May 29 th, the patient was put under the influence of ether 